\title{
CUERPOS ALTERADOS Y MUNDOS ALTERADOS: SEMIÓTICA DE LAS OTRAS CORPOREIDADES
}

\author{
ALTERED BODIES AND ALTERED WORLDS: \\ SEMIOTICS OF THE OTHER CORPOREITIES
}

José Enrique FINOL

Universidad de Lima

jfinol@ulima.edu.pe

\section{Dobrila DJUKICH DE NERI}

Universidad del Zulia

dobriladaria@gmail.com

La realidad del mundo de la vida exige de mí, por así decir, la re-explicitación de mi experiencia, e interrumpe el curso de la cadena de evidencias Alfred Schutz (1973)

Resumen: Como continuación de investigaciones anteriores sobre el cuerpo, en el presente análisis se proponen y desarrollan los conceptos de cuerpos alterados y mundos alterados, los cuales nos servirán para fundamentar una hipótesis, según la cual existe una relación estrecha y dialéctica entre unos y otros. Después de resumir representaciones previas 
del cuerpo en la fotografía y en la escultura, la investigación se centra en las representaciones corporales hechas en algunas obras de Picasso y de Botero, para lo cual se revisan definiciones de corporeidad que orienten el análisis. Finalmente se propondrá una clasificación de los tipos de relaciones entre cuerpos alterados y mundos alterados.

Palabras clave: Cuerpos alterados. Mundos alterados. Corporeidad. Picasso. Botero.

Abstract: As a continuation of previous investigations about the body, in the following analysis we propose and develop the concepts of altered bodies and altered worlds, which will be useful to base a hypothesis according to which there is a close and dialectic relationship between one another. After summarizing previous corporeal representations in photography and sculptures, this research focuses in bodily representations made by Picasso and Botero. To carry out the analysis, we take a look to some definitions of corporeity. Finally, we will propose a classification of types of relations between altered bodies and altered worlds.

Key Words: Altered bodies. Altered worlds. Corporeity. Picasso. Botero.

\section{LA CORPOSFERA: LAS SEMIOSIS CORPORALES}

En la presente investigación nos proponemos dar continuidad a temas anteriores y, en tal sentido, en una primera parte, introduciremos y ampliaremos algunos aspectos de las significaciones del cuerpo ya tratados previamente (Finol, 2015; Finol, 2016). Se trata de avanzar en cuestiones propias de las significaciones y experiencias corporales que contribuyan a desarrollarlas y profundizarlas en el marco del dinámico y complejo universo de sentidos que, en concordancia con Lotman (1996), hemos llamado la Corposfera, uno de los territorios de la Semiosfera. Como se 
verá, en investigaciones anteriores hemos trabajado sobre la fotografía y la escultura, y hemos analizado cuatro de las diversas representaciones artísticas, contemporáneas, del cuerpo. En el marco de esas investigaciones, en el presente análisis trataremos un corpus pictórico para referirnos a otras nuevas corporeidades, vistas en sus contextos históricos, para relacionar lo que denominaremos cuerpos alterados con sus correspondientes mundos alterados.

Como hemos dicho en otras oportunidades, el cuerpo, todo y en todo momento, incluso a nuestro pesar, significa. Gracias a nuestro cuerpo semiotizamos el mundo; desde él parten y a él retornan los sentidos del mundo. Para Martin-Juchat, "El cuerpo está en el origen de nuestra capacidad para semiotizar el mundo" (2001: 56); lo que confirma Contreras: "La semiosis ocurre a condición del cuerpo" (2012: 15); y también Rosales: "El cuerpo aparece como fundamento de la significación" (2010: 12). Así, pues, el cuerpo no es solo un conjunto de lenguajes, códigos o sistemas de signos; más allá aún, el cuerpo es origen y destino de las diversas formas en que semiotizamos el mundo para darle, en el marco de variados y dinámicos contextos, un sentido particular. Es en esa inserción dinámica entre cuerpo y mundo donde, a la manera fenomenológica, se generan y comunican los sentidos que atraviesan el entorno donde ocurren y discurren nuestra semiotizaciones particulares.

Las múltiples acciones y representaciones del cuerpo y su inserción activa en el mundo constituyen una de las más poderosas formas de significación y comunicación en la vida social y cultural de los seres humanos, inserción que se sostiene dialécticamente en nuestra presenciaacción en el mundo, ya que, si ciertamente, como dice Schutz, "Toda acción en mi mundo circundante lo modifica" (1973: 39), también, agreguemos nosotros, toda modificación del mundo circundante, en particular cuando este es alterado, es decir, sale de los límites flexibles de su "normalidad", modifica nuestras relaciones con él y con nuestro propio cuerpo. Allí radica la confrontación/integración dialéctica, progresiva o destructiva, entre el sujeto y el mundo. Por ello, en una investigación anterior, abordamos 
el tema de las ausencias del cuerpo y de cómo estas se representaban en la fotografía y en la escultura (Finol, 2016); para ello desarrollamos una propuesta en la que se confrontaban las ausencias del cuerpo con su sobrepresencia en algunas expresiones culturales contemporáneas.

\section{LA PRIMERA HIPÓTESIS: DE LA SOBREPRESENCIA DEL CUERPO A SUS AUSENCIAS}

En el marco general de las omisiones o elipsis del cuerpo hablamos de cuerpos ausentes, sustituidos, camuflados o fracturados. En los primeros, tenemos una ausencia absoluta y, sin embargo, sabemos que el cuerpo, invisible, está allí; podemos "leerlo" gracias a los espacios y objetos que lo significan; en el segundo caso, el cuerpo no está presente, pero está un modelo que lo sustituye, bien sea por semejanza o por un índice metafórico del mismo. En el tercer caso, si bien el cuerpo está presente, lo encontramos fundido con su entorno, formando parte integrante de él, siendo, en buena medida, un componente más de ese entorno. Finalmente, gracias a la tridimensionalidad de la escultura es posible para un artista representar cuerpos rotos, fragmentados; son cuerpos que han perdido su unidad, lo que los hace poderosamente significativos. Veremos brevemente las ilustraciones de cada uno de estos cuatro casos, lo que nos introducirá a la propuesta de lo que llamamos cuerpos alterados y de su relación dinámica y simbólica con lo que llamaremos mundos alterados.

\subsection{Cuerpo ausente}

En esa primera investigación contrastamos la sobrepresencia del cuerpo, su saturación en los medios, la publicidad y las redes sociales, con sus ausencias, desapariciones y fracturas. Por ejemplo, si observamos bien la foto 1, veremos que en ella aparecen significados carentes de significantes corporales directos, visibles, explícitos. En efecto, la fotografía de Videla expresa al cuerpo sin que este esté presente, un 
fenómeno que no es solo producto de las experiencias previas aprendidas, sino también de las formas ergonómicas del objeto representado; se trata de un conjunto de significados que se actualizan en la medida en que el espectador "completa" el mensaje con aquello que no está presente en la silla, pero que la experiencia y la memoria reclaman.

Si observamos con detalle la fotografía, veremos que la significación corporal que ella expresa se potencia gracias al espacio doméstico, interno (la sala) y externo (el jardín), pero también gracias al espacio de transición constituido por la puerta, un límite que separa espacios domésticos, pero también una frontera que los vincula. Aunque no lo vemos, aquí hay un cuerpo que, con sus tránsitos entre un espacio y otro, y con su permanencia en ellos les ha dado un sentido que es posible representar y significar, aunque el cuerpo esté (in)visible.

\subsection{Cuerpo sustituido}

Un fenómeno similar ocurre cuando la fotografía representa la ausencia del cuerpo a través de un objeto que le es propio; se trata de una metáfora visual que, inevitablemente, guarda una relación de contigüidad con aquello de lo cual el objeto, aunque sea ocasionalmente, forma parte. En la foto 2 esa contigüidad objeto $\rightarrow$ cuerpo se amplía y refuerza gracias al recurso de la sombra, un signo de enormes posibilidades semióticas que rompe la presencia del cuerpo para rearticularla con nuevos sentidos que se fecundan gracias a los múltiples contextos donde ella aparece. El fotógrafo, Pol Hervàs Úbeda, no está forzando la realidad, sino que la completa; y, a fin de cuentas, es esa "completitud" la que fecunda no solo elementos estéticos, sino también sociales y culturales. En ese juego estético entre cuerpo y sombra, entre presencia y ausencia, intervienen los códigos culturales que buscan, en cierto modo, des-representar para mejor representar.

Se podría decir, utilizando la terminología lingüística, que en la foto 2 los zapatos actúan como una suerte de deixis exofórica, un dispositivo 
que opera cuando la entidad referida está fuera del texto. Aquí, los zapatos actúan como un deíctico, pues aluden al cuerpo humano que no está explícitamente presente. Los dispositivos de exoforización responderían a una sobre saturación de la presencia.

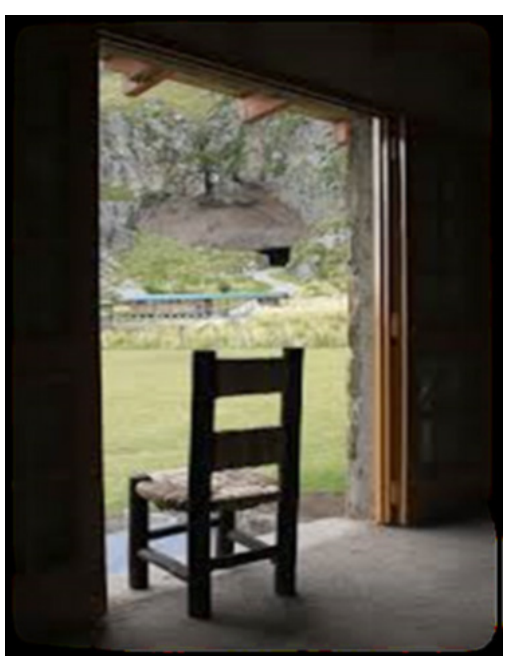

Foto 1. La silla vacía. Autor: Edgardo Videla. Tomada de http://ow.ly/ vTZQ301OYDj [19/12/2017].

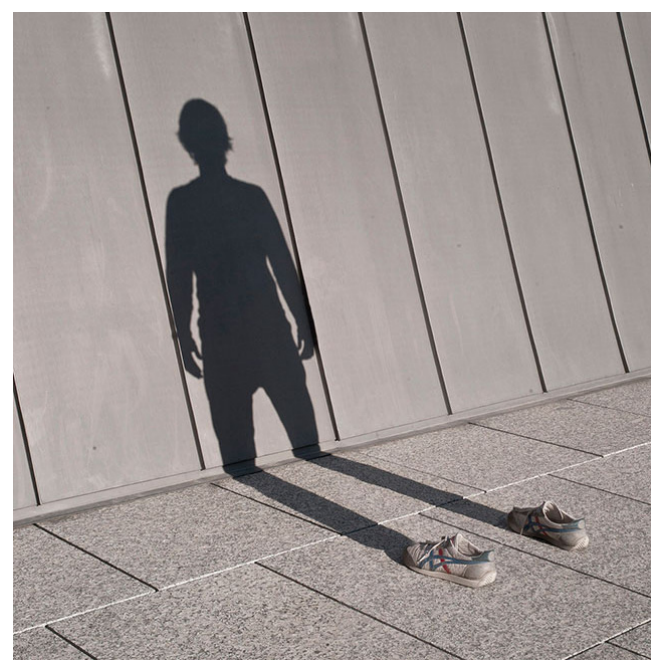

Foto 2. De la serie Yo No Estoy Allí. Autor: Pol Hervàs Úbeda. Tomada de http://www.freshlandmag.com/2013/06/07/ fotografias-pol-ubeda-hervas/ [19/12/2017].

\subsection{Cuerpo camuflado}

Otra forma de desaparición o invisibilización del cuerpo es el camuflaje, tal como se observa en la obra del escultor y fotógrafo chino Liu Bolin (Fotos 3 y 4), quien usa su propio cuerpo para integrarse al paisaje urbano. A diferencia del caso anterior, Bolin no des-representa el cuerpo, no lo hace ausente, sino que lo mimetiza con la ciudad, lo sume en ella para hacerlo parte de ella; ese proceso mimetizador podría interpretarse, al menos, de dos maneras. Por un lado, la ciudad que incorpora y absorbe al urbanita y lo hace parte sustancial de ella o, en un caso más extremo de esta misma interpretación, el espacio urbano devora al ser humano. Por otro lado, en una segunda interpretación, esta representación fotográfica 
nos mostraría a un ser humano que, voluntaria o involuntariamente, se simbiotiza con su entorno; el personaje se esconde en él, porque, insatisfecho, desea escapar de la realidad propiamente humana y social. Se trataría de una tercera realidad que se ubica entre el espacio urbano y el espacio corporal; un fenómeno sincrético donde los simbiontes, cada uno, dejan de ser lo que son para devenir una suerte de tercer espacio.

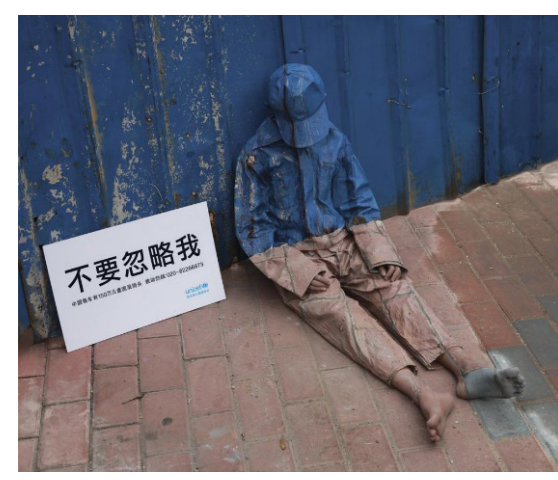

Foto 3. Autor: Liu Bolin. Tomada de http://www.laotramirilla. com/2015/06/liu-bolin-el-hombreinvisible.html [19/12/2017]

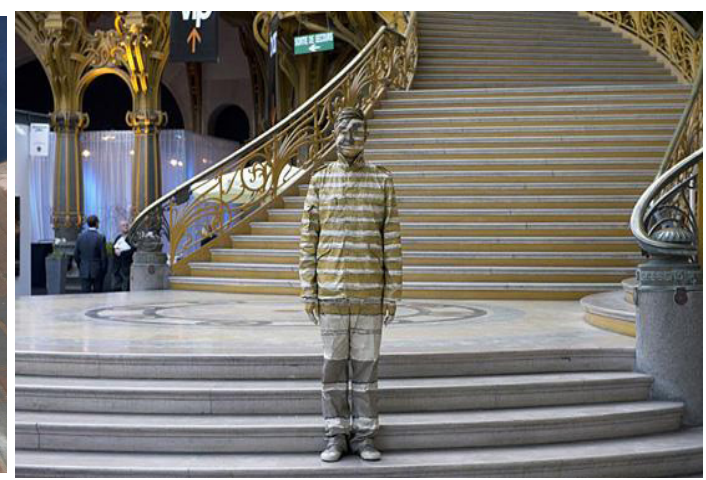

Foto 4. Autor: Liu Bolin. Tomada de https:// es.paperblog.com/liu-bolin-camuflandoseen-arquitectura-camoflage-works-1548170/. Fotos de la serie "Escondido en la ciudad" [19/12/2017].

En la fusión entre espacio urbano y cuerpo el primero cobra un sentido transformador del segundo, pues no es este quien lo marca o lo sobre determina, sino que el espacio es quien lo marca, lo incorpora y, en cierto modo, lo absorbe. Bolin propone así una corporeidad urbana en la que el cuerpo humano se hace parte de la ciudad.

\subsection{Cuerpo fracturado}

Bruno Catalano, con su grupo escultórico en bronce titulado "Los Viajeros", presenta otra forma de desaparición o ausencia parcial del cuerpo; aquí el escultor nos muestra cuerpos fracturados, incompletos, con 
personajes de edad avanzada, con expresiones tristes que llevan maletas, un tipo de objeto que claramente simboliza el viaje, pero también la partida y la separación. Se trata de personajes rotos que encarnan las rupturas de la vida, de la separación y la distancia, del desapego y la ausencia forzadas. Si en la foto No. 1 el espectador debe completar la escena con la imagen de un cuerpo que solo está anunciado o prefigurado, en estas esculturas (Fotos 5 y 6) el espectador debe completar las partes del cuerpo que faltan, debe re-armar, imaginariamente, lo que, aunque no se ve ni se toca, se imagina.
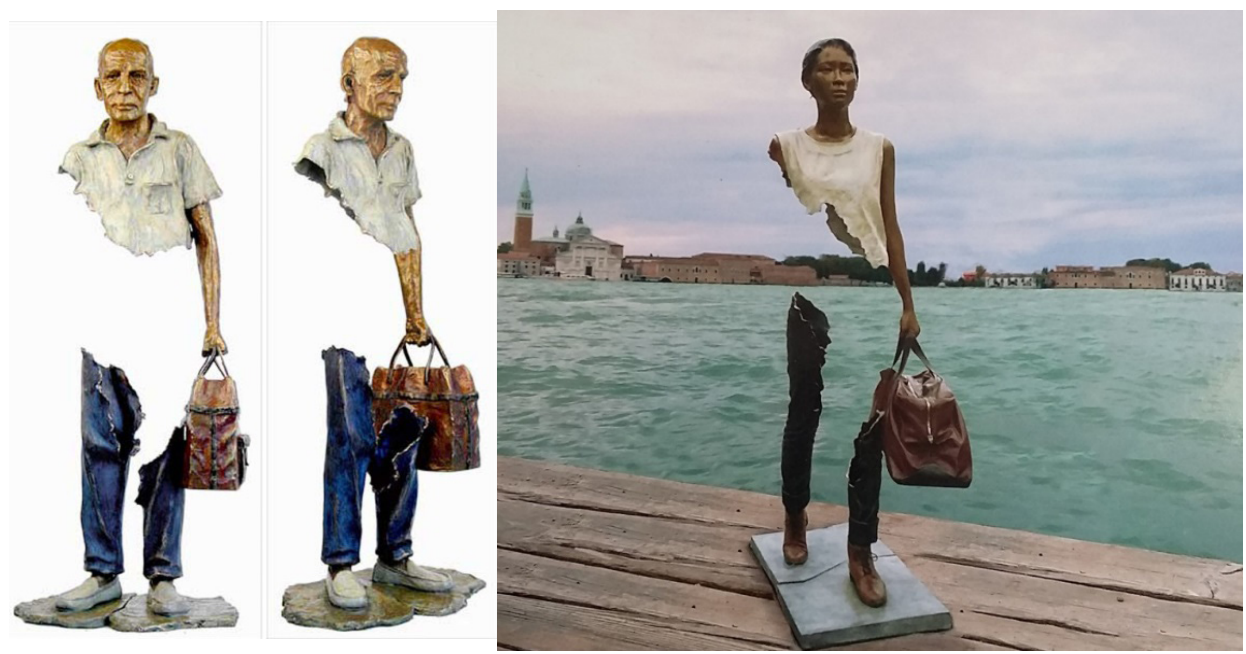

Fotos 5 y 6. "Los viajeros", de Bruno Catalano. Tomadas de http:// arquiarte2011.blogspot.com/2012/02/bruno-catalano-los-viajeros.html [19/12/2017].

Como en los anteriores casos, el artista obliga al espectador a ser parte no solo del mensaje de los viajeros tristes representados, sino también de los cuerpos rotos. Esta subversión corporal es también una subversión de las miradas que buscan lo que no está y que, entonces, deben completarlo. 


\section{EL SELFIE COMO SATURACIÓN VISUAL DEL CUERPO...}

En esa primera hipótesis la desaparición o invisibilización del cuerpo sería una respuesta, desde el arte, a su sobresaturación en la sociedad del espectáculo, creada por las redes sociales y, en particular, por el selfie. Hay autores, como Byung-Chul Han, que afirman que "El selfie es, exactamente, este rostro vacío e inexpresivo. La adicción al selfie remite al vacío interior del yo. Lo que genera la adicción al selfie no es un auto enamoramiento o una vanidad narcisista, sino un vacío interior." (2015). Para nosotros, sin embargo, tal como lo hemos expuesto previamente (Finol y Finol, 2008), esta auto fotografía es una expresión que intenta superar el anonimato y rescatar la existencia del cuerpo, de su identidad y de la vida propia; se trata, sin duda, de una expresión neo-narcisista ${ }^{1}$, aunque su interpretación no puede limitarse a ello; pero, al mismo tiempo, es una afirmación propia frente al anonimato y contra la sobrepresencia de los otros, en particular de los famosos, de las estrellas y de los políticos, de los deportistas y de la realeza de oropel y lujo. Es frente a la saturación visual y cultural del cuerpo en la sociedad del espectáculo - en las redes sociales, la publicidad, los medios, el cine, etc.- que algunos artistas han reaccionado para construir una nueva corporeidad y también una renovación de la visualidad.

\section{LA SEGUNDA HIPÓTESIS: CORPOREIDAD Y ALTERACIONES DEL CUERPO}

En esta segunda hipótesis, complementaria de la anterior, se correlacionan dos modelos de corporeidad en la sociedad del espectáculo.

${ }^{1} \mathrm{El}$ "estoicismo, en las prácticas estéticas que suponen la presencia del dolor, y el hedonismo, en la búsqueda del placer, son las dos formas constitutivas, contemporáneas, de lo que se denominará el neo-narcisismo" (2008: 383); "un neo-narcisismo fundado, por un lado, en la propia contemplación del cuerpo y, por el otro, en su exhibición y cotejo con los modelos impuestos" (Finol y Finol, 2008: 399). 
El primer modelo es el que corresponde a la auto representación del cuerpo, un proceso que, como hemos visto, se expresa con nitidez en el fenómeno selfie. La auto representación la habíamos visto a menudo en la historia del arte figurativo, particularmente en los llamados autorretratos que muchos artistas realizaron; también los habíamos visto en cuadros donde el artista se incluye a sí mismo en la escena pintada. Ejemplos clásicos de este último fenómeno son los numerosos auto retratos de Rembrandt y también "Las Meninas", de Velázquez, quien, en una suerte de "selfie pictórico", se incluye en la escena, paleta en mano, pintando el propio cuadro. En fotografía, la primera autofoto había sido tomada por Robert Cornelius en $1839^{2}$.

El segundo modelo, como veremos, es el que llamaremos la hetero representación, específicamente la de cuerpos alterados. Ahora bien, ¿cómo se relacionan las anteriores representaciones del cuerpo con lo que aquí llamamos cuerpos alterados? ¿Cómo se relacionan tales cuerpos con lo que llamaremos mundos alterados? Antes de abordar los fenómenos de hetero representación, creemos conveniente reflexionar sobre el concepto de corporeidad, lo que nos permitirá abordar con mayor rigurosidad el concepto de cuerpos alterados y de su expresión en obras de Picasso y Botero. Se ha elegido la obra de estos autores, entre otros que también han trabajado la temática corporal, por considerarlos representativos del trabajo artístico con el cuerpo, de su distinto origen nacional y, finalmente, por representar corrientes artísticas diferentes. Tales criterios pretenden plantear la eventualidad de una posible aplicación posterior de los conceptos propuestos, más allá de tendencias artísticas y orígenes nacionales.

\footnotetext{
${ }^{2}$ Para ver algunas de las más antiguas selfies fotográficas consultar The Guardian (21/07/2014). En diciembre de 2018 aparecerá un número especial de la revista Punctum consagrado a la semiótica del selfie.
} 


\section{1. ¿Qué es la corporeidad?}

Para Fuenmayor:

La corporeidad podría entenderse como el simulacro de la propia construcción del cuerpo y de los textos donde un número limitado de elementos (...) permiten crear la representación psíquica de contenidos y su traducción en lenguajes desde un mismo sistema semiótico. La corporeidad no es cuerpo visible sino el sistema organizador de lo visible, hablable o pensable y como tal, puede verse la gramática inconsciente con que fue construido (2005: 125).

Como se ve, esta definición hace énfasis en "la representación psíquica de contenidos", lo que la asocia a una visión lacaniana; $y$, por otro lado, acentúa la dimensión conceptual de lo corpóreo: "la corporeidad no es cuerpo" físico sino un sistema semiótico regido por una gramática inconsciente.

Para Rosales Cuevas, si bien la corporeidad tiene inicialmente que ver con nuestra morfología física, también está decisivamente marcada por lo social:

Existe una comunidad humana fundada en el hecho de que compartimos una corporeidad con similares arquitecturas, con similares funcionamientos y atravesadas siempre por la manera en que el grupo social en que vivimos nos enseña a valorar lo sentido y experimentado (2010: en línea).

Para nosotros la corporeidad es:

el conjunto de los imaginarios dinámicos que una sociedad, gracias a la acumulación de sus experiencias, en un momento 
histórico determinado y en una cultura concreta, atribuye al cuerpo, considerado como un objeto semiótico inserto en un mundo que lo caracteriza y lo significa, y al que, al mismo tiempo, el cuerpo, gracias a su riqueza comunicativa, también caracteriza y semiotiza. (...) la ambivalencia del cuerpo, se deriva de su inserción dialéctica, fronteriza y transgresora entre su condición de fenómeno natural y su construcción como fenómeno cultural (2015: 10).

Así, pues, los imaginarios corporales reunidos y expresados en un texto - pintura, literatura, fotografía, escultura, etc.- responden a una visión social y cultural del cuerpo; ellos no pertenecen a una sustancia física, aunque se expresan gracias en ellas, y son, por el contrario, tributarias de formas creadas, compartidas y socializadas. De este modo, la(s) corporeidad(es) no se limita(n) solo a lo corporal propiamente dicho, sino que es (son) inseparable(s) de sus condiciones históricas, culturales y sociales; de allí que el análisis de la realización textual de las semiosis corporales sea, necesariamente, el resultado de la inserción de los textos en sus contextos o, a la inversa, de la irrupción de los contextos en los textos.

\subsection{El cuerpo hetero representado...}

Como ya hemos señalado, la auto representación corporal tiene su máxima expresión contemporánea en el selfie, palabra escogida unánimemente como "Palabra del año" por los Diccionarios Oxford en $2013^{3}$. En nuestras sociedades contemporáneas, frente a las perfecciones

\footnotetext{
${ }^{3}$ La palabra "selfie", aparentemente de origen australiano, según Oxford Dictionary, y aún no aceptada por la real Academia de la Lengua Española, no solo ha mostrado una sobreabundancia de apariciones en distintas redes sociales, sino también ha tenido una productividad lingüística sorprendente: "Its linguistic productivity is already being seen by the creation of a number of related terms, showcasing particular parts of the body like helfie (a picture of one's hair) and belfie (a picture of one's posterior); a particular activity_-welfie (workout selfie) and drelfie (drunken selfie), and even items of furniture-
} 
del cuerpo en la moda, el cine, la publicidad y en el propio selfie, distintas iniciativas han surgido para crear nuevas visiones del mismo, nuevas maneras de significar y comunicar; son procesos identitarios que se expresan en distintos tipos de alteraciones del cuerpo que se extienden desde el tatuaje y el piercing hasta el branding, las perforaciones y los trasplantes, pasando por las escarificaciones y las mutilaciones. Autores como Nateras Domínguez (2005), Rodríguez Ortiz (2009), Maldonado Rivera (2010), Sastre Cifuentes (2011), Carmen et al., 2012), Rojo Ojados (2017), entre muchos otros, han analizado las alteraciones corporales, su origen, simbología y procesos identitarios.

También algunos artistas han generado nuevas visiones del cuerpo, expresión de otras maneras de concebirlo y de establecer su lugar en el mundo; se trata de expresiones que, de un modo u otro, están contextualmente vinculadas a sus historias, colectivas y personales. Los artistas, con su enorme capacidad innovadora, inventores o reinventores de nuevas formas, colores y composiciones; creadores de nuevas percepciones y miradas, rompen cánones establecidos y crean los propios. Los historiadores y críticos de arte se han ocupado extensamente sobre el tema del cuerpo en artistas reconocidos. Dos ejemplos clásicos de esas otras concepciones del cuerpo las encontramos en las obras de Picasso y Botero.

\section{ALTERACIONES DEL CUERPO}

Las alteraciones del cuerpo tienen una larga historia; una de sus fuentes principales la encontramos en las antiguas mitologías. En la griega, por ejemplo, se hallan numerosas alteraciones corporales, muchas de ellas basadas en la combinación entre formas animales y humanas, como en el

shelfie and bookshelfie. In fact, it seems that the words know no bounds, although some do seem rather forced, with multiple interpretations, like the apparent delfie (where the $\mathrm{d}$ could stand for dad, dog, double, or rather inexplicably dead) or melfie, with the $\mathrm{m}$ being explained as Monday, moustache, male, or mum" (2013). 
caso, entre muchos otros, del Minotauro, el Centauro, Cécrop, Tritón, el hipocampo, las harpías, las sirenas, etc. En la visión mitológica griega, las fronteras entre animalidad y humanidad no están rígidamente marcadas y, por el contrario, las intersecciones morfológicas entre una y otra son constantes y comunes. Como afirma Lantero Moreno, en "la relación hombre-animal en el imaginario griego [...] existe un tránsito continuo y una trascendente expresión de la naturaleza, la animalidad se despliega para el hombre como elemento relevante de un lenguaje simbólico" (2018: 189).

Esas alteraciones corporales se continúan hoy en el cómic impreso y en la novela gráfica ${ }^{4}$, así como en sus versiones cinematográficas, donde, gracias al uso de convenciones fijadas previamente, aparecen numerosos personajes creados por empresas como Marvel, en los que abundan, ya no la combinación de rasgos morfológicos entre humanos y animales, sino las representaciones de humanos, hombres y mujeres, que tienen súper poderes, cuyo origen es de diferente naturaleza, entre ellos Hulk, The Thing, Goliath, Giant Girl, Green Light, Aquaman, Superman.

En las distintas expresiones artísticas, las alteraciones corporales expresan un interés por crear nuevas percepciones e interpretaciones del cuerpo. Ellas reflejan otras perspectivas de lo que es la corporeidad, y, al mismo tiempo, producen la construcción interpretativa de nuevas miradas. Esas nuevas perspectivas las encontramos en las esculturas de

\footnotetext{
${ }^{4}$ Para ver un análisis de los elementos fundamentales de la estética corporal en los cómics, ver Cuñarro y Finol (2013a), donde los autores realizan "un inventario de las características físicas más comunes en el cómic, específicamente en Marvel Civil War, lo cual nos ha permitido concluir que existe un numero finito de cuerpos arquetípicos [...] clasificados en atléticos, heroicos y colosos, para los personajes masculinos; y atléticas, afroditas y heroicas, para los personajes femeninos". La investigación realizada señala que "el fenotipo de cada grupo está estrechamente relacionado con aspectos fundamentales de su carácter; su forma corpórea es una manifestación de su ser interior; es decir, su belleza es una manifestación de su nobleza" (2013a: 47). Para un análisis de las convenciones del cómic ver Cuñarro y Finol (2013b), quienes concluyen que "La lectura de una novela gráfica es al mismo tiempo un acto de percepción estética y una persecución intelectual, en ella se entrelazan el régimen artístico (perspectiva, simetría, líneas) y el régimen literario (gramática, trama, sintaxis)" (2013: 267).
} 
cuerpos femeninos de Henry Moore (1898-1986), por ejemplo, en la Figura reclinada, de 1951, donde el cuerpo desarrolla volúmenes y modos distintos de articular el cuerpo y sus componentes.

Pero incluso casi sesenta años antes de Moore, ya Edvard Munch (1863-1944) había realizado en la plástica esa progresiva alteración del cuerpo que se acentuará y ampliará más tarde. Su famoso cuadro El Grito (1893) distorsiona la silueta humana para que esta refleje la angustia y el miedo, una distorsión que no se limita a lo corporal, sino también al contexto ambiental del cuadro mismo, donde, además, aparecen como contrastes otros dos personajes, cuyas siluetas se perciben "normales" (Foto 7). El cuadro prefigura, para nosotros, lo que hemos denominado cuerpos alterados como expresión de mundos alterados.

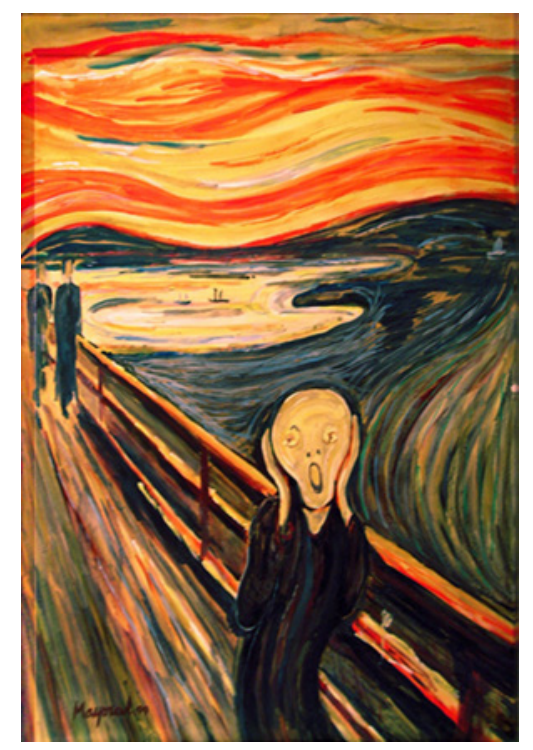

Foto 7. El grito (1893). Edvard Munch.

Preferimos el concepto de alterado en lugar de modificado, este último muy común y frecuentemente usado en los medios, gracias a la serie Tabú Latinoamérica transmitida por el canal de televisión de 
la National Geographic. En español la propia etimología de la palabra modificar evidencia cambios que respetan el orden y la continuidad. En efecto, según el DRAE, modificar viene del latín modificāre y tiene como significado 'regular', 'ordenar', 'moderar'. En cambio, por su origen, el término alterado (lat. tardío alterāre, cambiar, derivado de alter, cuyo componente léxico principal es allius = otro), significa "convertirse en otro" o "devenir otro". La alteración supone un tránsito que va desde un estado a otro, desde un ser a otro; cuando esa transformación es progresiva y se desarrolla sobre una línea evolutiva de tiempo más o menos larga, podríamos hablar de cambio; mientras que al hablar de transformación nos referimos a un cambio desarrollado intempestivamente o, cuando menos, sobre una corta línea no-evolutiva de tiempo. Como se ve, es en la transición y en sus etapas, su larga o corta duratividad, donde radica la diferencia entre cambio y transformación.

Las alteraciones corporales no tienen, para nosotros, las connotaciones de los cuerpos de los que se ocupa la Teratología; no se trata de los monstruos 5 , cuyas caracterizaciones, en general, carecen de direcciones o sentidos políticos. La noción de monstruo está relacionada con deformidades físicas socialmente repugnantes: "En s'écartant violemment de la norme physique, que la société a imprégnée dans notre éducation sociale et psychologique, un être difforme, qu'il soit simple, double ou bisexué, nous subjugue car il réveille en nous des peurs refoulées" (Martínez, 2008: 99). Lo que llamamos cuerpos alterados tampoco se inscribe en los procesos de corpofobia, los cuales tienen que ver no solo con el descontento con el propio cuerpo, lo que se conoce como dismorfofobia, una patología que a menudo conduce a la cirugía plástica, sino también con la negación del cuerpo del otro y la búsqueda de su destrucción ${ }^{6}$. Llamamos cuerpos alterados a aquellos que se apartan

${ }^{5}$ Para un análisis detallado del cuerpo-monstruoso, ver Ancet (2006).

${ }^{6}$ Un estudio de la Academia Estadounidense de Cirugía Facial, Plástica y Reconstructiva (2017) indicaba que en 2017 un 55\% de los cirujanos plásticos faciales tuvo pacientes que querían verse mejor en los selfies un aumento del 42\% en comparación con 2013. Así mismo, la Oficina Nacional de Estadística de Reino Unido señalaba que "el 27\% de los 
abiertamente, por un lado, de los cánones de la proporción ${ }^{7}$, entendida como la relación equilibrada entre las partes y el todo (Botero); y, por el otro, de los cánones contemporáneos de la belleza (Picasso).

Las alteraciones corporales significan, a diferencia de los fenómenos teratológicos y corpofóbicos, la construcción de nuevas corporeidades, pues si bien ellas están atadas a una noción básica, fundamental, de lo que es el cuerpo, implican también una modificación de los imaginarios que están asociados, gracias a experiencias perceptivas e interpretativas previas, con la noción de cuerpo humano; se trata de una indagación visual y experiencial sobre los parámetros situacionales e históricos de lo que, colectiva o individualmente, hemos interpretado como cuerpo. Es justamente sobre esos paradigmas socialmente aprendidos que las propuestas de los artistas son un esfuerzo de subversión y ruptura; para ello los artistas rompen, en cierto modo, la dicotomía entre lo corporal biológico y lo corporal cultural para proponer nuevas soluciones, tanto en lo uno como en lo otro. En efecto, como en el caso de Moore, el artista no solo violenta la morfología natural del cuerpo sino, sobre todo, subvierte la constitución social del mismo. Son esas alteraciones las que conducen a corporeidades diferentes.

\subsection{Cuerpos alterados: Picasso}

Lui qui a osé toucher aux canons du visage, du corps de la femme et de l'homme, bouleverse sinon l'ordre de la vie, du moins l'ordre de la représentation inscrite,

adolescentes que utilizan las redes sociales durante más de 3 horas al día tiene síntomas de problemas de salud mental" (BBC, 23/04/2018).

${ }^{7}$ Para Policleto (siglo V a. C.), por ejemplo, la altura canónica del cuerpo debía ser equivalente a siete y media cabezas; para Lisipo (siglo IV a. C.) debían ser ocho cabezas. Una altura mayor a las señaladas correspondía a los atletas, los héroes y divinidades. Siglos más tarde, Da Vinci, en El hombre de Vitruvio (1490), también estudia las proporciones ideales del cuerpo. 
depuis des siècles, à l'image de Dieu

Henri Yeru y Michelle Say (1986)

En Figures au bord de la mer (1931), por ejemplo, Picasso altera desmesuradamente la morfología del cuerpo humano. Mientras Manet al pintar "Olimpia" (1863) dice que ha pintado lo que él ha visto (“ $J$ 'ai fait ce que j'ai vu"), Picasso "no pinta lo que él ve" (Giraud, 2017), sino que reinventa al cuerpo humano, lo que comienza con Les demoiselles d'Avignon y continúa con Femme se coiffant (1940). (Foto 8).
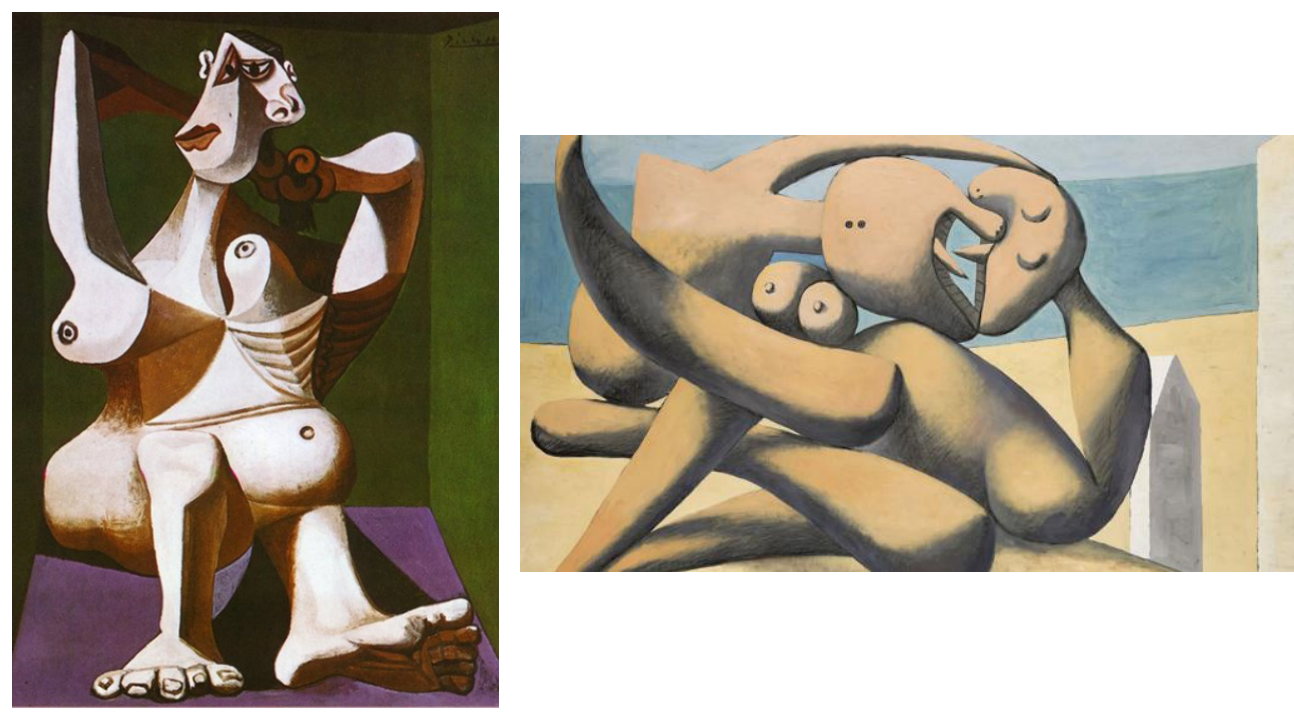

Foto 8 P. Picasso. Femme se coiffant (1940).

Foto 9. P. Picasso. Figures au bord de la mer (1931).

Esas alteraciones tienen que ver con la organización morfológica del cuerpo, pues los componentes del rostro se des-articulan y se des-ordenan, de modo que boca, ojos y la cabeza misma se desplazan en direcciones inesperadas y se rompen en formas que para el sentido tradicional serían "monstruosas". Es justamente contra ese sentido tradicional, propio del canon pictórico tradicional, que el artista trabaja, pues de lo que se 
trata es de alterar el cuerpo para convocar y provocar otras visualidades $\mathrm{y}$, en consecuencia, nuevos sentidos ${ }^{8}$, unos sentidos que, según nuestra hipótesis, están vinculados a aquellos que se originan en mundos alterados, los cuales constituyen el contexto histórico donde el artista vive, pero que se caracterizan por una disrupción capaz de modificar sustancialmente las relaciones sociales, políticas y económicas de convivencia en determinadas sociedades; son mundos trascendentemente rotos donde, como dice Sontag, "la guerra expulsa, destruye, rompe y allana el mundo construido" (2003: 8).

\subsection{Una ruptura con el canon: cuerpo feo, desemejante y desproporcionado}

Picasso, al igual que el cubismo, rompe con el canon tradicional de la representación del cuerpo basado en la belleza, la semejanza y la proporción (Leoni-Figini, s/f). Podríamos, por una reflexión a contrario, decir que en buena parte de la obra de Picasso el cuerpo es feo, desemejante y desproporcionado. Como se sabe, el concepto de lo bello no es inamovible ni inmutable, sino que se corresponde con épocas, culturas y situaciones; de modo que el artista busca crear un nuevo patrón de belleza que se corresponda más con su tiempo, su cultura y su situación. ¿Por qué el artista rompe con esas tradicionales variables de la representación corporal? ¿Es posible establecer una vinculación entre los cambios en esas tres variables pictóricas y el contexto histórico en el cual el artista vive y las obras se crean? Sin duda, esa ruptura con el canon cambia la percepción y los imaginarios sobre el cuerpo, en consecuencia, crea una nueva corporeidad basada en nuevas lógicas del cuerpo:

\footnotetext{
${ }^{8}$ Melius ha desarrollado un análisis detallado del sentido erótico en el cuerpo alterado, tal como este aparece en El pintor y su modelo (1927), en el cual concluye que "the work of picturing for Picasso consists of the imaginative deformation of a body already there in the service of eroticized visual interest" (2015: 46).
} 
- Cuerpos desnudos (y no vestidos)

- Cuerpos deformes (no morfológicamente conformes)

- Cuerpos maleables (y no rígidos)

Esa corporeidad diferente que Picasso construye de manera sistemática es un esfuerzo estético de representación y comunicación que, según nuestra hipótesis, se articula a su experiencia como artista, pero también a su estar en el mundo, un mundo terriblemente marcado, en primer lugar, por la Segunda Guerra Mundial (1939-1945), al cual Picasso no fue, ni podía, ser indiferente. Cuando ese conflicto comienza, el artista tiene 58 años y morirá a los 92. Femme se coiffant (Foto 8) es una obra realizada justo un año después de su inicio. Previamente, en segundo lugar, Picasso ha visto/vivido la Guerra Civil Española (1936-1939), cuando tenía 55 años y había alcanzado su madurez artística. Un año después del inicio de la guerra en su país, pintará su obra más comprometida y revolucionaria: Guernica, una obra en la que los dos grupos de actores representados, humanos y animales, ya muestran, junto a los gestos de la desesperación y angustia, rasgos corporales alterados, diferentes al canon morfológico tradicional ${ }^{9}$. El mismo año, 1937, había realizado grabados semejantes al cómic, que tituló Sueño y mentira de Franco, en los cuales, junto a uno de sus "poemas río", denunciaba la tiranía del dictador español y se burlaba de él. Picasso, sumergido en ese mundo alterado de la Guerra Civil Española, también expresa su rechazo a la oligarquía y a la iglesia española con un pequeño cuadro pintado también en 1937, donde el cuerpo humano, "hecho a imagen y semejanza de Dios", es transfigurado:

${ }^{9} \mathrm{El}$ Guernica no es el único cuadro que Picasso pinta sobre la guerra. Como bien señala Llorente Hernández, “en 1945 lo hizo con su cuadro El osario, pintado tras conocerse el horror de los campos nazis de concentración y de exterminio; dos años después con el Monumento a los españoles muertos por Francia, y en 1951, cuando pintó Masacre en Corea, una versión del cuadro El 3 de mayo de 1808 en Madrid: Los fusilamientos en la Montaña del Príncipe Pio de Goya" (2012: 76). 


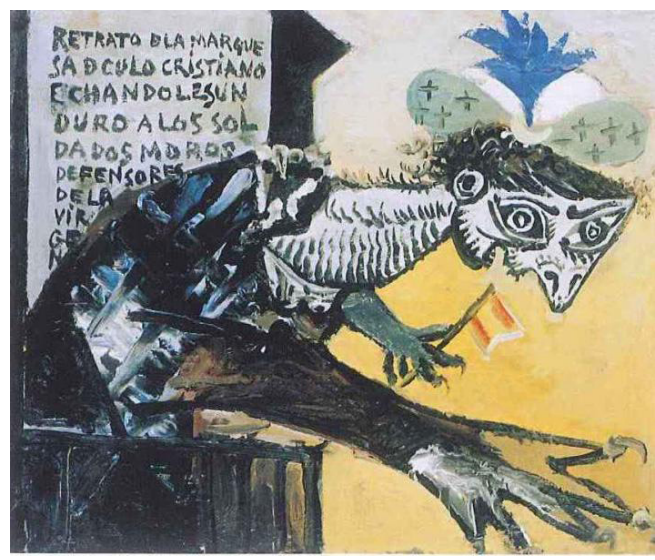

Foto 10. Retrato de la marquesa de culo cristiano echándole un duro a los soldados moros defensores de la virgen. P. Picasso (1937). Tomado de http:// catalogo.artium.org/book/export/html/5941 [19/12/2017].

En el cuadro anterior (Foto 10), emanado de su compromiso con la República española, se observa ese encuentro entre cuerpos alterados y mundo alterados que, de paso, revela que el compromiso social o político no por ello deja de ser arte, como ya lo demostraría el pintor con Guernica, una obra anclada a un hecho y a un tiempo concretos pero que, sin duda, se ha elevado más allá de ellos ${ }^{10}$.

En una entrevista el propio artista ha dicho:

¿Por qué cree usted que fecho todo lo que hago? Es que no basta con conocer las obras de un artista. También hay que saber cuándo las hizo, por qué, cómo, en qué circunstancias. Sin duda, existirá

\footnotetext{
${ }^{10}$ En esta interpretación diferimos del análisis de Yeru y Say, para quienes el Guernica "vise plus aux mythes et aux symboles qu'à la réalité historique" (1986: 349), una afirmación que contradice la conclusión final de su propio trabajo, según la cual Picasso "a maintenu en ses structures, quoique revisitées, sans aller jusqu'à la rupture, la place de l'homme, même brisé, contre le malaise d'une société occidentale déséquilibrée" (1986: 355). En efecto, los mitos y símbolos del Guernica son recursos que privilegian, sobre el tiempo, la condición de lo histórico; es eso, justamente lo que hace de la obra una trascendental pieza de arte, sin por ello contradecir su excepcional expresión histórica y social.
} 
un día una ciencia, que quizá se llame la ciencia del hombre, que aspirará a ahondar en el hombre a través del hombre creador (Ginzburg en Artium, 2012 [redondas nuestras]).

También Esteban Leal reconoce la influencia y los trazos de esos mundos alterados, no solo los histórico-sociales sino también los personales, en la obra del artista malagueño:

Los acontecimientos de la vida privada de Picasso, junto a los sucesos políticos que atribularon al continente europeo en el periodo de entreguerras, se fusionan en los motivos creados por el pintor en estos momentos, para dar lugar tanto al propio Guernica como a sus bocetos y post scriptum (s/f).

Los mundos alterados producen en quienes los viven ese salto de estilo a los que Schutz se refirió como estilo de vivencia: “....al estilo de vivencia le corresponde esencialmente una tensión específica de conciencia, tal 'salto' va acompañado por una experiencia conmocionante, provocada por la alteración radical de la tensión de conciencia" (1973: 43 [cursiva nuestra]).

\section{BOTERO: VOLUMEN Y SENSUALIDAD...}

El arte es una acusación permanente Fernando Botero (2007)

La larga producción de Botero en pintura y escultura, con personajes y animales de gran volumen, ya se inicia en 1952, con En la costa, y 1958, con su cuadro La camera degli sposi. Incluso el mismo Jesucristo adquiere volúmenes inesperados, tal como lo pinta en el Cristo crucificado, de 2011 (Foto 12). 


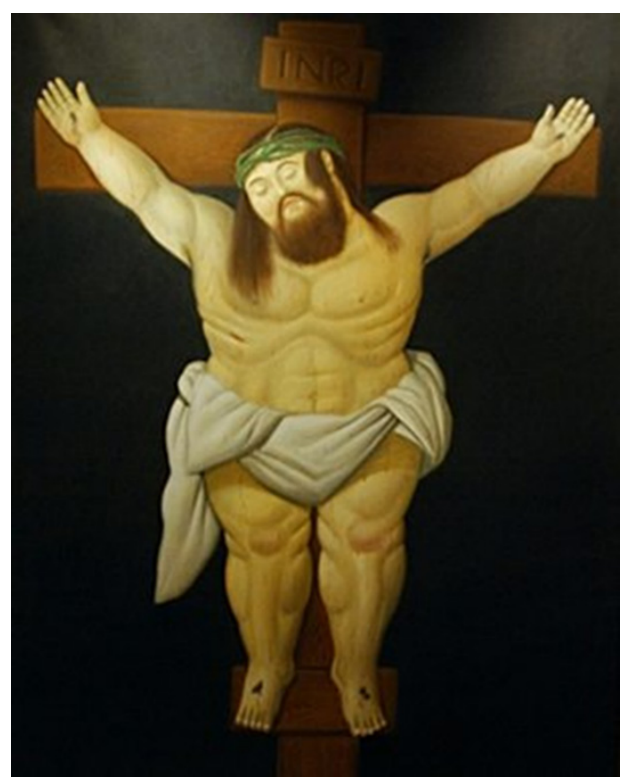

Foto 12. Cristo crucificado (2011)

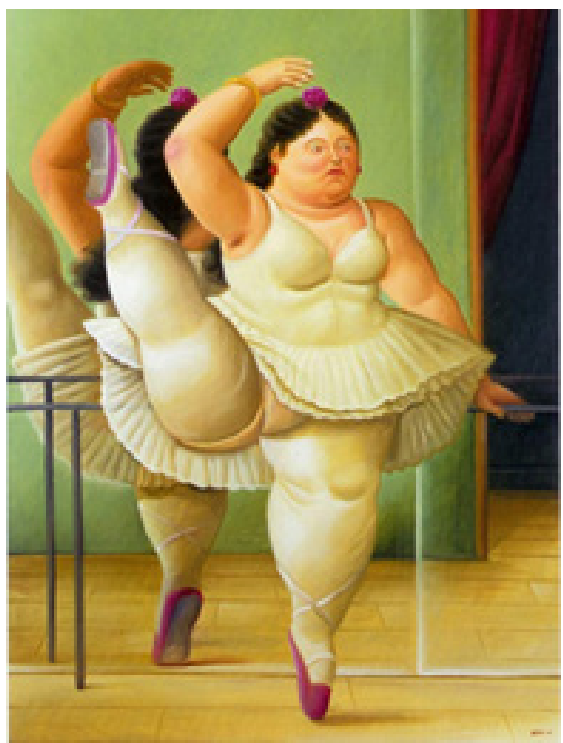

Foto 13. Bailarina en la barra

Frente a las críticas superficiales que lo reseñan como un pintor de "gordas", Botero responde: "No he pintado una gorda en mi vida. He expresado el volumen, he buscado darle protagonismo al volumen, hacerlo más plástico, más monumental, como si fuera casi comida, arte comestible. El arte debe ser sensual" (Botero, 2012). Botero reconoce su propósito de alterar las dimensiones del cuerpo: el propio artista clasifica su arte figurativo, de formas hinchadas y personajes orondos, como "forma expresiva divergente", donde el volumen, como se observa en La Bailarina en la barra (Foto 13), encarna una corporeidad presentada como sinónimo de sensualidad. Esa sensualidad, sin embargo, no es la de los cuerpos de la moda, del selfie o de la publicidad; es una sensualidad cenestésica, pues crea una sensación sobre el estado del propio cuerpo.

\subsection{Sensualidad sinestésica...}

Además de esa sensualidad cenestésica, también es una corporeidad 
sinestésica, pues, como en el ejemplo de la bailarina, el exceso de volumen no se articula al sentido de peso sino, por el contrario, convive con el de gracia y agilidad. Ahora bien, mientras Picasso pinta en los primeros tres cuartos del siglo XX (1901-1973), en un marco histórico caracterizado por las dos guerras mundiales y por la Guerra Civil española, Botero pinta y esculpe en la segunda mitad del mismo siglo e inicios del siglo XXI (sus primeras obras son de1948).

\section{2. ¿mundos alterados?}

Si los conflictos mundiales y la guerra civil española marcan la vida y parte de la obra de Picasso, ¿la larga guerra de guerrillas, de los paramilitares y del narcotráfico —y también, como veremos, las torturas durante el conflicto en Irak - marcan la vida y parte de la obra de Botero? ¿Son algunas de sus obras respuestas artísticas a esos acontecimientos? ¿Son sus representaciones alteradas del cuerpo expresiones de mundos alterados? Esa sensualidad sinestésica que hemos señalado ¿es una propuesta más feliz frente a mundos alterados?

Como se sabe, hay conjuntos de obras de Botero que son una respuesta explícita y clara a situaciones históricas y políticas concretas. En tal categoría entran sus obras sobre las torturas por parte de soldados norteamericanos contra ciudadanos iraquíes (Foto 14) durante la invasión en 2002 a Irak en la prisión de Abu Ghraib. Sobre esa serie de cuadros el artista ha dicho que "Uno no puede quedarse callado cuando suceden estas cosas y dejar que solo la prensa y los políticos las aborden. El artista también es un ser humano y se preocupa, y lee los periódicos y tiene sentimientos [...] Si uno oculta esto, entonces el arte no existe" (Botero, 2007).

En esa serie de 78 cuadros $^{11}$, Botero presenta a hombres voluminosos,

\footnotetext{
${ }^{11}$ Botero ha declarado que no piensa vender ninguna de las pinturas de la serie $\mathrm{Abu}$ Ghraib, pues considera que es "inmoral enriquecerse del sufrimiento humano". Espera donarlas a un museo en los Estados Unidos que las albergue en su colección permanente.
} 
cuyos cuerpos desnudos o en ocasiones vestidos con ropas de mujer sufren no solo el tormento físico, sino también el abuso psicológico y moral (Fotos 14, 16 y 17). Un detalle muy significativo en los cuadros, tomado de las fotos que aparecieron en algunos medios (Foto 15), es el vendaje de los ojos, un recurso que priva al flagelado de la posibilidad de ver y que incrementa la angustia de esperar sin saber cuál ataque viene y de dónde viene. La privación de la vista le permite también al torturador no-ver en los ojos de la víctima el dolor, la angustia y la ansiedad del torturado; una estrategia que le facilita al primero deshumanizar al segundo, convertirlo en objeto, cosificarlo. El volumen de los cuerpos adquiere en estos cuadros un papel protagónico: se convierte en un dispositivo semiótico gracias al cual mientras esos cuerpos son más grandes y extensos, la tortura y el tormento, también, parecen hacerse más grandes e intensos. El volumen corporal y la extensión de la piel son territorios conquistados, vejados y torturados y, en consecuencia, expropiados. Como una cosa más.
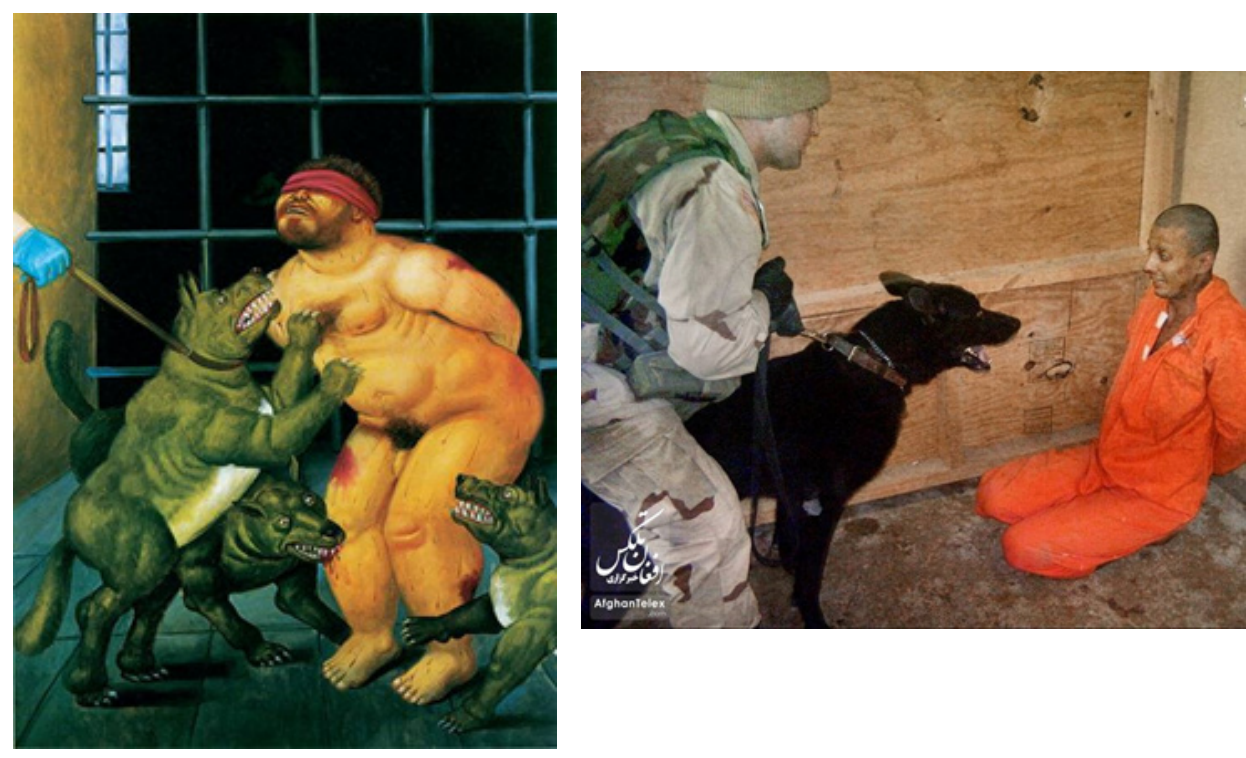

Foto 14. Abu Ghraib.

Foto 15. Las torturas en la prisión de Abu Ghraib (2003). 
Frente a ese mundo alterado que fue la cruenta invasión a Irak, seguida y multiplicada incesantemente por los medios de difusión en casi todo el mundo, Botero, con la misma calidad y maestría artística con la que ha pintado siempre, realiza la serie pictórica Abu Ghraib, y en ella presenta, a diferencia de otros cuadros, unos cuerpos alterados, ya no en su volumen sino en sus posiciones, gestos y en sus no-miradas; también en las direccionalidades de sus cuerpos: arrastrados, curvados, inclinados y rendidos; cuerpos flagelados, llenos de pánico y terror. Puede aplicarse aquí lo que mujeres colombianas, sistemáticamente violadas por guerrilleros, paramilitares y narcotraficantes, cuentan en el libro Expropiar el cuerpo: "Rompiendo la carne, se apropia a la persona" (Prada Prada, 2018: 142); o, si sustituimos en el siguiente párrafo "mujeres" por "hombres" veremos que una posesión y dominio similar se realiza en la violación y en la tortura: "Como suele ocurrir cuando los armados implantan su dominio, los cuerpos de las mujeres se convirtieron en objeto de apropiación, como una extensión del territorio a dominar" (Prada Prada, 2018: 171. Cursiva nuestra).
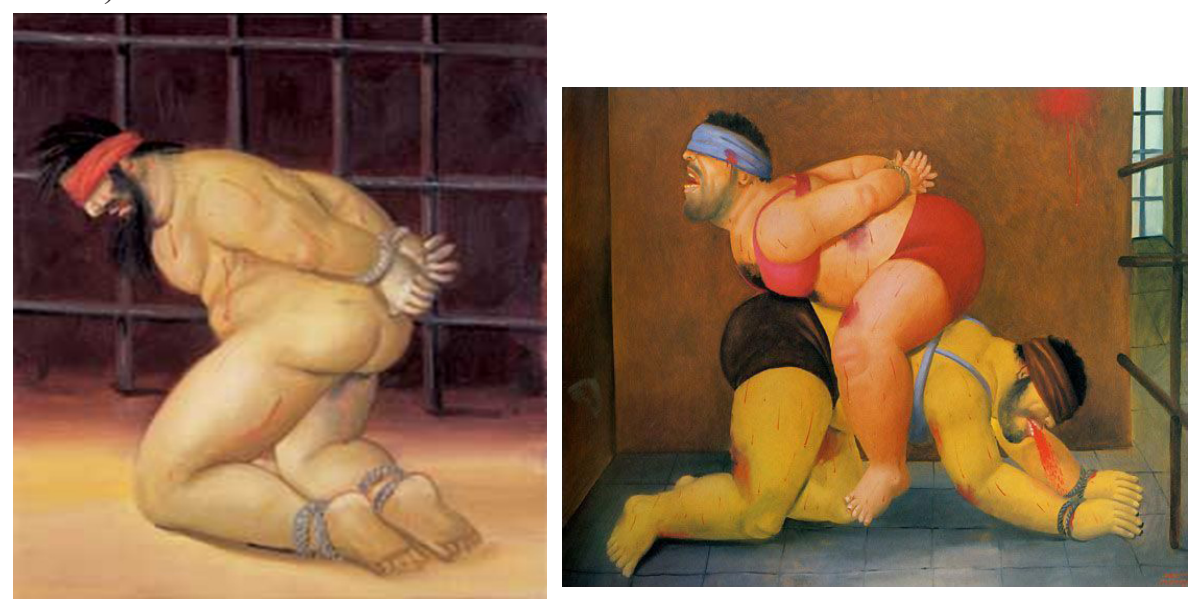

Fotos 16 y 17. Abu Ghraib, 2005. Serie de 78 cuadros sobre torturas realizadas por soldados norteamericanos en la prisión de Abu Ghraib, en Irak. 
Mucho más cercana a Botero y prolongada en el tiempo fue la triple guerra, guerrillera, paramilitar y de narcotráfico, que ha azotado a Colombia por más de cincuenta años; conflictos que, entre 1958 y 2012 habían dejado 220.000 personas asesinadas, 25.000 desaparecidas y 4.744.046 desplazadas, según el Centro Nacional de Memoria Histórica (2014). Ese mundo alterado, el de su propio país, no podía ser ajeno a Botero y a su compromiso humano. De esa relación vivencial nació la serie La violencia en Colombia, compuesta por 67 obras sobre la muerte y la guerra que forman parte de ese patrimonio histórico y político. En 2004, el artista se refería a esas obras en estos términos: "sentí un día que tenía que pintar, hacer una declaración del horror que sentía ante ese panorama del país" (Diario El País, 04/05/2004). Botero abandonada así su tradicional posición ideológica: "Yo estaba en contra de ese arte que se convierte en testigo de su tiempo como arma de combate. Pero en vista de la magnitud del drama que vive Colombia, llegó el momento en el que sentí la obligación moral de dejar un testimonio sobre un momento tan irracional de nuestra historia" (González y Londoño, 2004: 58); una expresión con la que Botero confirma la afirmación de Schutz: "La realidad del mundo de la vida exige de mí [...] la re-explicitación de mi experiencia” (1973: 32).

En los mundos alterados colombianos, un artista sensible como Botero no podía ignorar la muerte. De hecho, varios de sus cuadros ya se preocupaban por ese tema, particularmente en obras como Obispos muertos (1965), El asesinato de Ana Rosa Calderón (1970) y en La corrida (1985). Ahora bien, a diferencia de los cuerpos desnudo de Abu Ghraib, en esta serie de pinturas el artista antioqueño presenta cuerpos vestidos, atravesados por balas, sorprendidos en medio de la fiesta por la muerte sin esperanza (Foto 18), o apilados como bultos con cuerpos perforados (Foto 19). Estos cuadros contrastan con las de los cuerpos en la playa o las de familias y niños felices; sus ojos parecen salir de sus órbitas y sus pechos muertos son la transformación originada por mundos alterados que Botero no puede ignorar porque, a fin de cuentas, el artista nació y vivió en ellos, son parte de su historia, tanto personal como colectiva. 

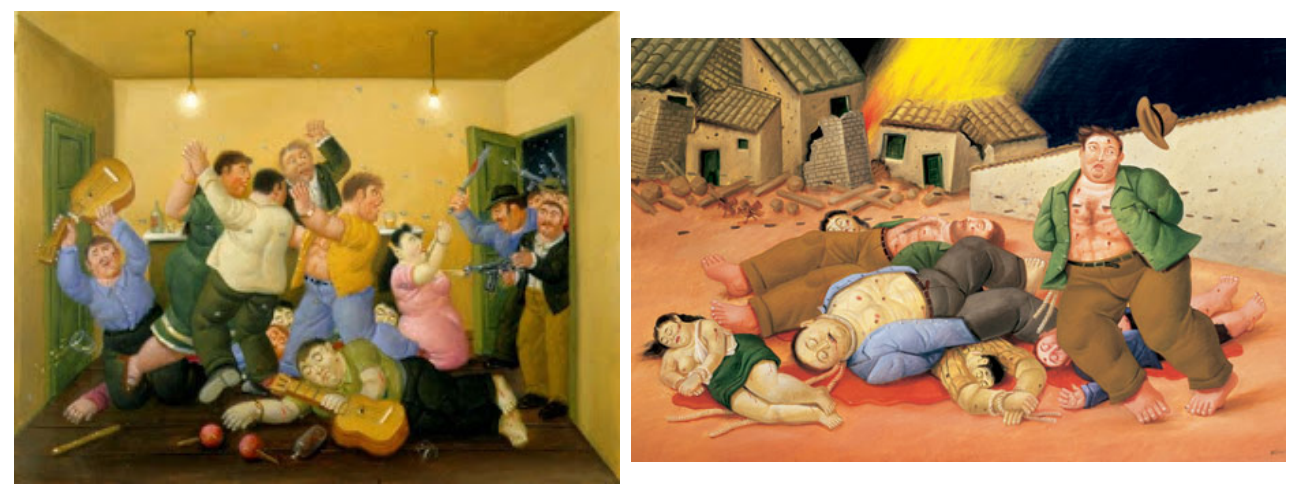

Foto 18. Masacre de Mejor Esquina (1997).

Foto 19. Masacre en Colombia (2000).

La constancia y la permanencia de las figuras voluminosas de Botero hacen que esos cuerpos puedan ser conceptualizados como lo que hemos llamado súper signos; es decir, un objeto semiótico que, por su redundancia y permanencia, por su densidad y capacidad para representar significados concretos, por su reiterativa utilización, trasciende un texto, para actualizarse en varios textos pictórico y también, como en el caso de Botero, en textos escultóricos. El súper signo atraviesa varias obras de un autor a través del tiempo, lo caracteriza, y en sus diferentes realizaciones permanece casi como una marca de identidad.

\section{TRES NIVELES DE SEMIOTIZACIÓN...}

$\mathrm{Si}$, como dijimos antes, el concepto de corporeidad y los imaginarios que lo definen están estrechamente vinculados a "un momento histórico determinado y a una cultura concreta", es lícito suponer que esos contextos semióticos se expresan, de un modo u otro, en los dispositivos semióticos que los artistas manejan (Fig. 1). En otros términos, en las producciones y representaciones corporales realizadas en el arte habría que considerar siempre, al menos, tres niveles de semiotización: 


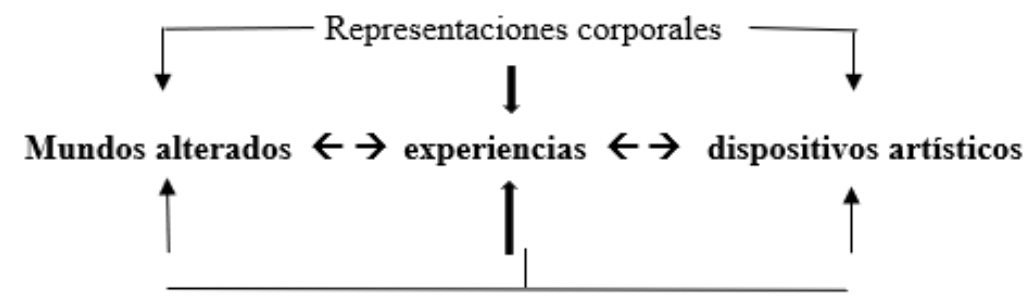

Figura 1

Esos tres niveles de semiotización tienen a las experiencias como centro irradiador, constituidas por una conjunción dinámica entre contextos (mundos alterados) y textos (obras de arte), donde los cuerpos, desde su morfología, desde sus miradas y movimientos, forjan una interrelación, cuya clave de interpretación no es exclusiva del texto, sino que proviene, de modo dominante, de los contextos. En otras palabras, es en esos contextos y desde y hacia las experiencias, individuales y colectivas, en conjunción con los dispositivos artísticos, que el artista ha reconocido en el cuerpo un modo de comunicar otros sentidos del mundo, mundos vividos, salidos de su ritmo ordinario para explosionar la vida de sus habitantes.

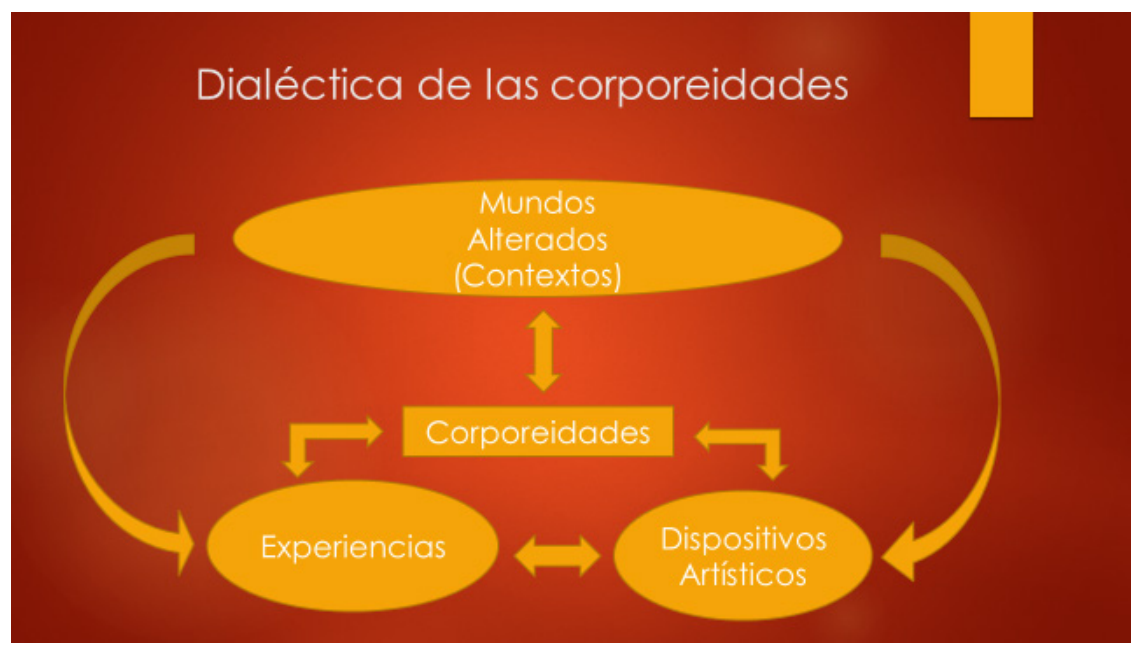

Figura 2. Dialéctica de las corporeidades. 
Naturalmente, esas alteraciones corporales y espaciales que se dan en mundos alterados, tienen límites. Uno de ellos es la legibilidad misma del texto, sea este visual o verbal. ¿Hasta dónde se puede deformar la imagen de un cuerpo para que ya no sea visualmente legible, reconocible y decodificable como tal? También tiene límites contextuales que permiten lecturas más o menos amplias. ¿Qué pasa, por ejemplo, con un observador de la obra de Picasso que no conociese su vida personal la situación histórica durante la cual vivió? Si bien no cambiaría para nada la potencialidad significativa de su obra, sí cambiarían los límites de la interpretación de ese observador. Si observase el "Guernica" (1937), de Picasso, y no conociese el bombardeo realizado sobre ese pueblo el 26 de abril de 1937, durante la Guerra Civil Española, por parte de la Legión Cóndor alemana y la Aviación Legionaria italiana, ese espectador reduciría los límites de sus posibles interpretaciones; vería dolor, sufrimiento y angustia, pero no vería sus causas históricas, del mismo modo en que, por ejemplo, nuestras posibilidades interpretativas de Pedro Páramo, de Juan Rulfo, se verían limitadas si no conocemos los mitos y rituales que componen el culto a la muerte en México.

\section{CONCLUSIONES: ¿POR QUÉ EL CUERPO?}

Como hemos sugerido, mientras las fotos y esculturas vistas en la primera parte de este trabajo representan diferentes procesos de invisibilización del cuerpo, las obras de Picasso y Botero nos introducen en la dialéctica entre mundos alterados y cuerpos alterados; se trata de cuerpos que en su propia morfología reflejan y realizan algunas de las alteraciones del mundo en el que han nacido y donde sus autores, de modos y por causas diversas, traducen y en ocasiones transforman esas realidades.

Fotógrafos y escultores nos han mostrado representaciones e imaginarios corporales que van desde su invisibilización total hasta su fractura, pasando por su sustitución y camuflaje. En el caso de los dos 
artistas aquí analizados, Picasso y Botero, hemos visto dos formas de subvertir la visualización del cuerpo y, concomitantemente, la creación de otros sentidos y, en consecuencia, de otras corporeidades. Picasso ha desarticulado y des-organizado el cuerpo, mientras que Botero ha desarrollado su volumen, pero, sobre todo, en el caso de la serie Abu Ghraib, le ha dado una nueva gestualidad y posicionalidad, lo que le ha permitido, gracias a esos recursos, salir de las figuras felices y voluminosas que pueblan su obra para ofrecer, ya no la sensualidad plácida de sus cuadros tradicionales, sino la alteridad del dolor, la angustia y el terror.

En una tipología de las relaciones dinámicas entre cuerpos alterados y mundos alterados podrían sugerirse cuatro tipos de relaciones que podemos llamar de confirmación, en la que la relación se basa en la mímesis; de transgresión, en la que la relación se basa en una ruptura; de traducción, en la que uno de los términos de la relación, el cuerpo, decodifica al otro, el mundo; y de transformación, en la que el primero hace del segundo un otro, un tercero, alterando sus fundamentos. Esos cuatro tipos de relaciones se articulan, a su vez en textos y contextos que generan los sentidos buscados por los creadores; se trata de posibilidades procesuales que podríamos representar así (Fig. 3):

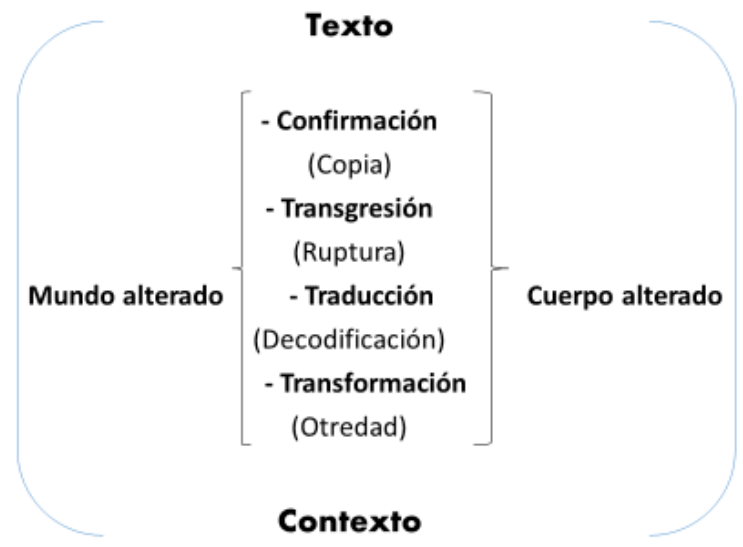

Figura 3: Tipología de las relaciones entre cuerpos alterados y mundos alterados. 
Ambos artistas nos han presentado otras corporeidades, con lo que nos han obligado a mirar y ver el cuerpo desde otros ángulos; ambos nos han conminado a ver "de otra manera" el cuerpo humano y, en consecuencia, a renovar los significados que le damos. La puesta en contexto, los mundos alterados, nos aproxima a la configuración de sentidos nuevos, inesperados, sorprendentes, a nuevos imaginarios que alimentan una concepción de "las estructuras del mundo de la vida" (Schutz, 1973), en las que las experiencias vividas determinan la necesidad de re-pensar y re-evaluar nuestra relación con ese mundo. Como hemos tratado de demostrar, esas alteraciones del mundo de la vida encuentran reflejos vivos - de-formados, trans-formados, re-elaborados, re-vividos - en las alteraciones de nuestro principal sistema de comunicación: nuestro cuerpo; lo que hace posible su utilización como instrumentos de reflexión, rebelión, protesta, lucha ${ }^{12}$.

Nos parece, pues, importante destacar en estas pesquisas sobre los imaginarios corporales que transitan entre el arte y las expresiones digitales como el selfie, que ellos, más allá de una simple relación causa-efecto, están intrínsecamente vinculados a las realidades histórico-sociales, en particular a las sociedades donde la imagen produce nuevas relaciones. En tal sentido, los conceptos propuestos, cuerpos alterados y mundo alterados, se presentan como herramientas para aproximarnos a una mejor comprensión de la condición relacional y dialéctica de la obra de arte y del mundo vivido, así como de su constante búsqueda por la construcción de sentidos diferentes, búsqueda que se asienta sobre la construcción de otras miradas.

\footnotetext{
${ }^{12}$ En la misma dirección, pero en otro escenario, hoy se recurre al uso del cuerpo como instrumento de lucha política, tal como lo analizan Arenas Conejo y Pié Balaguer, quienes descubren en los plantones del 15M de 2011, en España, un uso "de la experiencia de 'poner el cuerpo en la plaza', una forma de política encarnada en el espacio público" (2014: 227); luego, siguiendo a Sutton, los autores señalan que "la resistencia y protesta políticas no se basan únicamente en grandes ideas o visiones, sino que van siempre acompañadas de un intenso compromiso corporal: hay que "'poner el cuerpo"” (2014: 239). Un fenómeno similar recoge el proyecto Poner el cuerpo. Activismos feministas y lésbicos en las calles de Madrid durante los años 70 y 80 (Conde Duque, 2017).
} 
Para aproximarnos al conocimiento profundo, sistemático y coherente de las nuevas culturas digitales y de lo que las redes sociales expresan y proponen sobre nosotros mismos y sobre nuestras sociedades contemporáneas, es útil confrontar esas representaciones con sus opuestos o, mejor, con sus complementarios. Mientras las redes sociales se saturan con los jóvenes cuerpos del selfie, de sus rostros y miradas, los fotógrafos y escultores los desaparecen, los invisibilizan o fragmentan para, por paradójico que parezca, hacerlos más visibles. Asimismo, mientras la publicidad, la moda y el selfie nos muestran los cuerpos perfectos, delgados y jóvenes, los artistas desarticulan la morfología corporal o cultivan sus excesos a través del volumen y la asimetría.

Esa constatación nos obliga, simultáneamente, a repensar la teoría, la metodología y el análisis semiótico, tradicionalmente marcados como "teoría de los signos", o como disciplina de los "procesos de significación" o de semiosis. Es por ello que hemos propuesto una visión dialéctica de los procesos de significación, de acuerdo con la cual nuestra disciplina no solo estudia los textos, sino que apunta al encuentro dialéctico entre textos y contextos, lo que nos obligaría a desarrollar mucho más la teoría de estos últimos. Finalmente, ¿por qué el cuerpo? ¿Qué nos dicen esas nuevas corporeidades? ¿Qué nos dicen de nosotros mismos y, sobre todo, qué nos dicen de la sociedad y de la cultura en la que vivimos? Creemos que el cuerpo, sus representaciones e imaginarios, es uno de los medios privilegiados para expresar las alteraciones del mundo que, en el caso de Picasso son la Segunda Guerra Mundial y la Guerra Civil española, y en el caso de Botero es la guerra de guerrillas, el paramilitarismo y el narcotráfico, en Colombia, y las torturas, en Irak. Como instrumento principal de semiotización del mundo, el cuerpo es un complejo expresivo que, de diversos modos, sintetiza significados que adquieren sentidos particulares al producirse en contextos particulares. Es en el marco de esos contextos histórico-sociales donde los nuevos sentidos corporales, lo que hemos definido como corporeidades, se fecundan.

Para las semióticas del cuerpo, lo que hemos llamado la Corposfera, 
la identificación de esas mutaciones y transformaciones, el registro de los dispositivos semióticos que allí operan, son un reto, una invitación a la reflexión no solo de la interpretación de su significado profundo, sino también de los modos de articulación de tales dispositivos y de los sentidos que producen.

\section{REFERENCIAS BIBLIOGRÁFICAS}

AMERICAN ACADEMY OF FACIAL PLASTIC AND RECONSTRUCTIVE SURGERY (2014). "Selfie Trend Increases Demand for Facial Plastic Surgery". https://www.aafprs.org/media/press_release/20140311.html [26/04/2018].

ANCET, P. (2006). Phénoménologie des corps monstrueux. Paris: Presses Universitaires de France.

ARENAS CONEJO, M. y PIÉ BALAGUER, A. (2014). "Las comisiones de diversidad funcional en el 15M español: poner el cuerpo en el espacio público". Politica y Sociedad 5.1, 227-245. https:// search.proquest.com/docview/1542385365? pq-origsite $=$ summon [25/04/2018].

ARTIUM (2012). "Catálogo de Guernica de Picasso: historia, memoria e interpretaciones". http://catalogo.artium.org/book/export/ html/5941 [17/04/2018].

BBC (2018). "Dismorfia de Snapchat: el fenómeno por el que cada vez más pacientes de cirugía estética aspiran a parecerse a sus propios selfies con filtros". 23 de abril 2018. http://www.bbc.com/mundo/ noticias-43864965 [25/04/2018].

BOTERO, F. (2007). “Fernando Botero y Abu Ghraib: 'No me pude quedar callado". Revolución 79, 25 de febrero.

(2012). "El arte debe ser sensual". Revista Arcadia. 08/10/2012. https://www.revistaarcadia.com/arte/articulo/el-arte-debe- 
sensual-fernando-botero/29801 [25/04/2018].

BYUNG-CHUL, H. (2015). "El cuerpo terso", en La salvación de lo bello.

Tomado de https://www.pagina12.com.ar/diario/suplementos/ radar/9-11320-2016-03-06.html [10/04/2018].

CARMEN, R., GUITAR, A. and DILLON, H. (2012). "Ultimate Answers to Proximate Questions: The Evolutionary Motivations Behind Tattoos and Body Piercings in Popular Culture". Review of General Psychology 16.2, 134-143.

CENTRO NACIONAL DE MEMORIA HISTÓRICA (2014). ¡Basta ya! Colombia: memorias de guerra y dignidad. Bogotá: Centro Nacional de Memoria Histórica. http://www.centrodememoriahistorica.gov. co/micrositios/informeGeneral/descargas.html [19/04/2018].

CONDE DUQUE (2017). "Poner el cuerpo. Activismos feministas y lésbicos en las calles de Madrid durante los años 70 y 80". https:// www.condeduquemadrid.es/programacion/poner-el-cuerpoagitar-los-archivos [25/04/2018/].

CONTRERAS, M. J. (2012). "Introducción a la semiótica del cuerpo: Presencia, enunciación encarnada y memoria". Cátedra de Artes 12, 13-29.

CUÑARRO, L. y FINOL, J. E. (2013a). "Imagen y cómic: un análisis sociosemiótico de la estética corporal en Marvel Civil War". Maracaibo: Universidad del Zulia. Colección de Semiótica Latinoamericana 10: Semióticas de la Imagen, 47-59. (2013b). "Semiótica del cómic: códigos y convenciones". Signa 22, 267-290.

ESTEBAN LEAL, P. (s/f). Guernica. http://www.museoreinasofia.es/ coleccion/obra/guernica [17/04/2018].

FINOL, J. E. (2013). "Nuevos escenarios en la Corposfera: Fotografía, selfies y neo-narcisismo". LIS. Letra, Imagen, Sonido11, 15-28. (2015). La Corposfera. Antropo-Semiótica de las cartografías del cuerpo. Quito: CIESPAL.

(2016). “'Tu cuerpo es el mensaje'. La Corposfera: cuerpo, ausencia 
y significación”. Situarte 11.20. 10-22.

(2018). "De l'événement à l'expérience. Une approche sémiotique". Degrés 173-174, e1-e14.

FINOL, J. E. y FINOL, D. E. (2008). “Discurso, Isotopía y Neo-Narcisismo: Contribución a una Semiótica del Cuerpo". TELOS. Revista de Estudios Interdisciplinarios en Ciencias Sociales 10.3, 383-402.

FUENMAYOR, V. (2005). "Entre cuerpo y semiosis: la corporeidad". Opción v. 21, 48, 121-154.

GIRAUD, C. (2017). "Peindre le corps, du canon à la déformation". Deuxième Temps 2. Disponible en https://deuxieme-temps. com/2017/01/14/dossier-corps-canon-deformation/ [22/08/2017].

GONZÁLES, B. y LONDOÑO, S. (2004). Botero en el Museo Nacional de Colombia. Bogotá: Villegas Editores.

LANTERO MORENO, B. (2018). "La relación hombre-animal en la mitología griega". Naturaleza y Libertad 10. www.revistas.uma. es/index.php/naturaleza-y-libertad/article/download/3666/3420 [16/04/2018].

LEONI-FIGINI, M. (s/f). Le corps dans l'œuvre. http://mediation. centrepompidou.fr/education/ressources/ENS-corps-oeuvre/ENScorps-oeuvre.htm [22/08/2017].

LOTMAN, J. (1996). La Semiosfera. Madrid: Ediciones Cátedra.

LLORENTE HERNÁNDEZ, A. (2012). "Otto Dix, Pablo Picasso y la pintura de guerra". Espacio, tiempo y Forma, Serie V, Historia Contemporánea, t. 24, 65-78. https://search.proquest.com/ docview/1436081856?pq-origsite=summon [24/04/2018].

MALDONADO RIVERA, C. (2010). "Desterritorialización del cuerpo. El tatuaje y la episteme de lo subjetivo". Perspectivas de la Comunicación 3.1, 73-80.

MARTIN-JUCHAT, F. (2001). "Anthropologie du corps communicant". Anthropologie et Communication: Revue MEI 15, 55-66.

MARTÍNEZ, A. (2008). 'L'Anatomie monstrueuse dans l'art contemporain". Corps 2008/1, 4, 99-104. https://www.cairn.info/ 
revue-corps-dilecta-2008-1-page-99.htm [19/04/2018].

MELIUS, J. (2015). “Inscription and Castration in Picasso's The Painter and His Model, 1927". October Magazine 151, 43-61. http:// xu5ze2uw6h.search.serialssolutions.com [24/04/2018].

NATERAS DOMÍNGUEZ, A. (2005). "Los usos públicos del cuerpo alterado en jóvenes urbanos mexicanos". Polis 11. http://polis. revues.org/5751 [12/04/2018].

OXFORD DICTIONARIES. (2013). The Oxford Dictionaries Word of the Year for 2013 is selfie! https://en.oxforddictionaries.com/word-ofthe-year/word-of-the-year-2013 [12/04/2018].

PRADAPRADA, N. (2018). Expropiar el cuerpo. Bogotá: Centro Nacional de Memoria Histórica. http://www.centrodememoriahistorica.gov. co/publicaciones-cnmh/expropiar-el-cuerpo [19/04/2018].

RODRÍGUEZ ORTIZ, R. (2009). "El cuerpo como objeto de arte". https:// roxanarodriguezortiz.com/2009/08/31/el-cuerpo-como-objeto-dearte/ [12/04/2018].

ROJO OJADOS, A. (2017). Modificaciones corporales extremas: Una aproximación sociológica al fenómeno de las Modificaciones corporales extremas. Madrid: Asociación. Cultural y Científica Iberoamericana.

ROSALES CUEVAS, H. (2010). Cuerpo, arte y significación. http:// semiouis.blogspot.com/2010/03/cuerpo-arte-y-significacion.html [29/03/2017].

SASTRE CIFUENTES, A. (2011). “Cuerpos que narran: la práctica del tatuaje y el proceso de subjetivación”. Diversitas: Perspectivas en Psicología 7.1, 179-191.

SCHUTZ, A. (1973). Las estructuras del mundo de la vida. Buenos Aires: Amorrortu Editores.

SONTAG, S. (2003). Ante el dolor de los demás. Madrid: Santillana.

THE GUARDIAN. (2014). "The world's earliest selfies - in pictures". https://www.theguardian.com/artanddesign/gallery/2014/jul/21/ worlds-earliest-selfies-in-pictures-buzz-aldrin [25/04/2018]. 
YERU, H. y SAY, M. (1986). "Picasso à corps perdus". Études t.365.4, 343-355. http://gallica.bnf.fr/ark:/12148/bpt6k442029d/f57. image. $r=$ jesus.langFR. [18/04/2018].

Recibido el 27 de abril de 2018.

Aceptado el 23 de julio de 2018. 